\title{
Business Intelligence/Data Analytics for Online Fashion Store
}

\author{
Yash Vira \\ Department of \\ Computer \\ Engineering, \\ V.E.S. Institute of \\ Technology, \\ HAMC Complex, \\ Chembur, \\ Mumbai-400 074 \\ University Of \\ Mumbai
}

\author{
Mitesh \\ Vishwasrao \\ Department of \\ Computer \\ Engineering, \\ V.E.S. Institute of \\ Technology, \\ HAMC Complex, \\ Chembur, \\ Mumbai-400 074 \\ University Of \\ Mumbai
}

\author{
Nupur Giri, PhD \\ Department of \\ Computer \\ Engineering, \\ V.E.S. Institute of \\ Technology, \\ HAMC Complex, \\ Chembur, \\ Mumbai-400 074 \\ University Of \\ Mumbai
}

\author{
Devansh Mehta \\ Department of \\ Computer \\ Engineering, \\ V.E.S. Institute of \\ Technology, \\ HAMC Complex, \\ Chembur, \\ Mumbai-400 074 \\ University Of \\ Mumbai
}

\author{
Riya Punjabi \\ Department of \\ Computer \\ Engineering, \\ V.E.S. Institute of \\ Technology, \\ HAMC Complex, \\ Chembur, \\ Mumbai-400 074 \\ University Of \\ Mumbai
}

\begin{abstract}
An optimized web application that adheres to the manifold needs of customers of a fashion wear company (provided with a customizable catalogue for wholesale as well as retail customer). Being able to survive in times of highly competitive markets, to learn from the past and forecast the future, we are adopting Business Intelligence (BI) tools to analyse the reports i.e. BI tool which is an Eclipse based reporting system which is open source. This term is usually suffixed with designing and reporting in order to expand application functionalities. The paper explores the development of online fashion store and its reports using BI tools \& techniques.
\end{abstract}

\section{Keywords}

Business Intelligence, Eclipse.

\section{INTRODUCTION}

Today's business needs are ever increasing and to develop business solutions it is requisite to use proper tools and requirements. Business intelligence enables companies to use information gathered in order to quickly and constantly respond to the changes. In this digitally connected world, success depends upon understanding the customers, their needs, requirements, shopping patterns and the services they expect. Hence, an online fashion store with business intelligence tools is developed for analyzing various reports relating to sales and products. Also, this project target's "the industry (readymade garment manufacture)" is a one with high demand for web solutions, as they now face competition from growing e-commerce sites. Thus, trying to solve the problems they face creates a high possibility to transform the product into a start-up which effectively satiates this high demand.

Following are the 3 problem definitions:-

- Bridging the gap between wholesale customers in various regions around the world and the company's local office by providing web solutions for enabling customers to choose from latest catalogue without the need of periodic visits, to local showroom.(Business to Business)
- Extending the web solution to include retail customers as well and providing a functional ecommerce website that allows secure purchasing.

- Using BI tools to generate meaningful reports and allowing an insightful view to the manager, thus helping in making informed decisions.

These problem definitions helps to identify the problems faced by these garment or private industries and enables to provide necessary solution.

\section{LITERATURE SURVEY}

Business intelligence is the collection of techniques for the transformation of unstructured data into useful information for business specific purpose. The basic goal of BI is to interpret huge chunks of data. Some fundamental functions of business intelligence tools are online analytical processing, analytics, complex event processing, reporting. This Project is mainly focusing on Reporting technology of Business Intelligence. BI Applications and technologies can help companies to analyze following key points:

- Changing trends in market share \& Changes in customer behavior and spending patterns.

- Customers' preferences, Company capabilities and Market conditions.

\section{Business Intelligence today vs tomorrow:}

- BI today is like reading the newspaper: BI reporting tool on top of a data warehouse that loads nightly and produces historical reporting.

- BI tomorrow will focus more on real-time events and predicting tomorrow's headlines.

There are various tools for creating reports using BI, for the web application using these tools to leverage the power of social media and to generate actionable insights into consumer's preferences and behavior i.e. addressing customer expectations and enhancing their shopping experience.

Jasper Reports: Jasper Reports is the most popular open source reporting engine. Using java i.e. platform independent 
language enables to exact data from data source \& produce expected results as an outcome which can be exported in a variety of document formats such as HTML, PDF, Excel, Open Office and Word.

Pentaho: Another widely used BI tool is Pentaho. Expected reports are published in Pentaho-Platform through which managing, running and scheduling of reports can make task easier.

\section{BIRT: Business Intelligence and Reporting}

Tools i.e. BI tool based on the Eclipse integrated development environment (IDE) which is used to build and generate reports in Java/J2EE environment. BIRT mainly has two components which are: a report designer and a runtime component that can be added to the application server. BIRT provides data sets from where data is retrieved and converted to necessary reports.

Payment Gateway: The secure and reliable payment gateway is essential for ensuring the successful development of any ecommerce website. The cracking down of hash algorithm like MD5 imposes great potential security threat on the payment gateway. Hence payment gateways are very much important for making online payments. They provide safe and secure medium for communication between the application and customer. With safer payment gateways the customer trust is also enhanced. Paypal and CCAvenue payment gateways can be easily integrated within a web application.

\section{METHODOLOGY}

The method used is based on various technologies and tools. First it involves building a web application and then using BI tools for generating desired reports.

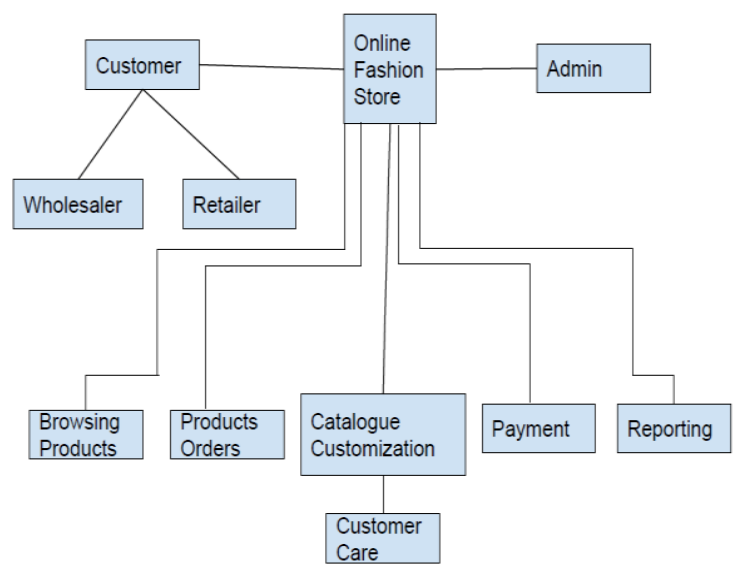

Figure 1: Proposed Design Structure

Following are set of tools or technologies required for our web application:

BIRT: Birt has wide community support and very flexible. It supports various database platforms for developing reports. Main goal of BIRT (BI Tool project) is to create a set of tools for analysis of data and reporting that are simple and easy to use, maintain, while supporting its extensibility and support. The major APIs are the Design Engine API (DE API), Report Engine API(RE API) and the Chart Engine API (CE API).

Why to use BIRT: BIRT is an open source Business Intelligence tool which is widely supported. BIRT has wide community that supports PHP as well as JAVA EE applications. Report compilation is not required as compared to Jasperreports and Pentaho (Other BI Tools). Eclipse Plugin is available for BIRT which can be directly incorporated.

The BIRT life cycle consists of 3 stages:

- Initialize

- Prepare

- Integrate

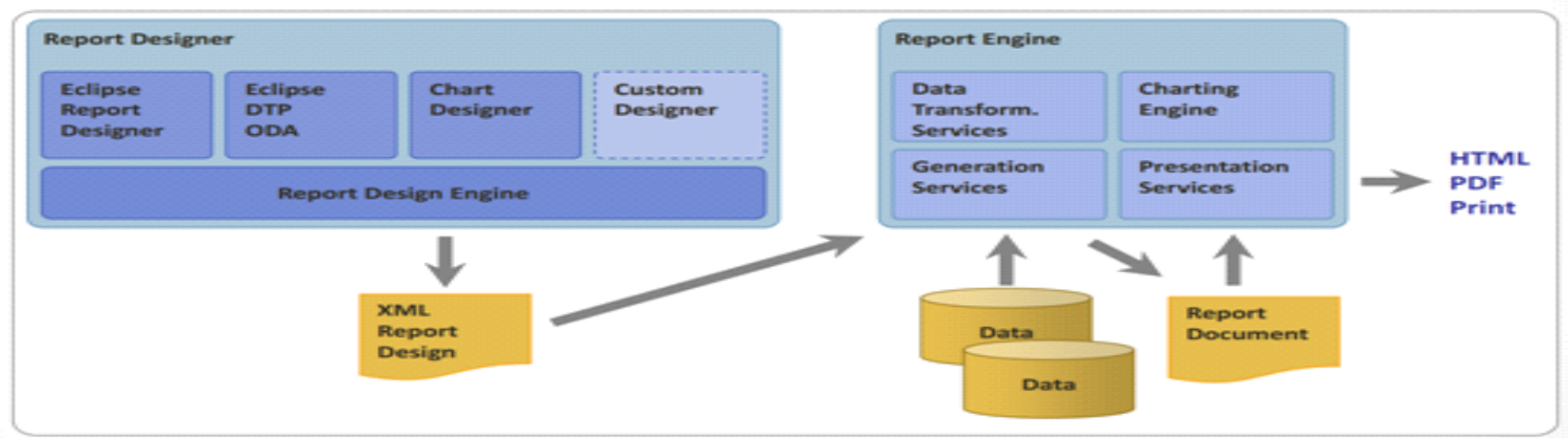

Figure 2: BIRT Architecture

\section{BIRT Key Capabilities are as follows:}

A. Simple to Complex Layouts: Listings, crosstab, dashboard, pixel-perfect, charts, grouping, advanced aggregations, sub-totals, calculations, Multi-section and sub-reports, embedded images.
B. Developer Productivity and Reusability: Library support for publishing and sharing components, Leverages common standards (SQL, HTML, JavaScript, Java, XML), Cascading Style Sheets.

C. Data Access in Compressive Manner: SQL 
databases, Web Services, Flat Files, XML, scripted data sources, multiple data sources in one design.

D. Desired Output Formats: HTML, PDF, Excel, Word, PowerPoint, Internationalization of labels and text, Bi-Directional language display.

E. Object Interactivity and Linking: Data driven hyperlinks, Drill-through charts and graphics.

F. Multiple Designs: Graphical layout and design, Query \& metadata editors Formatting Builder, Grouping Builder.

MYSQL: MySQL is popular choice for developing database for use in web applications. The entire database for website shall be stored using MySQL. Hence backend for the web application will be developed using MySQL.

JAVA EE: The Java Platform, Enterprise Edition is a widely used enterprise platform is widely used for developing web applications. The platform also provides an API and runtime environment for developing and running enterprise software, web services and web applications.

PHP: Php is also widely used for E-commerce applications. It also has support for developing shopping carts, paypal integration, admin side updating and many more features.

\section{DISCUSSIONS}

The web application should provide features for catalogue customization and availability to different types of users. Designing a report involves the following tasks. It is not required to perform the tasks in the specific order in which they are presented, but novice users to BIRT Report Designer or beginners learning to design reports can use the following task list as a starting point:

- Plan the report

- Start a new report design.

- Specify the data to use

- Lay out the report

- Format the report.

- Preview and test the report.

Online shopping allows us to shop from any vendor anytime, anywhere in the world but our application built for a particular company.

\section{CONCLUSION}

The online fashion store is serving the needs for both wholesalers as well as retailer (customers). The fashion store web application also provides solution for payment gateway. The report parameters are nothing but database attributes used to convert these attributes from database value to pictorial report formats. BI tools convert these database attributes into the type of Chart or Reports by inputting the data sets from the MySQL database. The online fashion store stores all the records of the items purchased by both the retail as well as the whole customers. The BI tools are used to develop reports relating to products and sales. These reports help the company to identify the key areas for business expansion and improvement.

Based on type of customer \& requirements following reports could be generated:-
Table 1: Reports for Online Fashion Store

\begin{tabular}{|c|c|}
\hline Reports & Description (Parameters) \\
\hline $\begin{array}{c}\text { Price Range } \\
\text { vs }\end{array}$ & $\begin{array}{c}\text { Compares the product price range vs the } \\
\text { sales made for that price range. }\end{array}$ \\
\hline $\begin{array}{c}\text { No. of Products } \\
\text { Delivered }\end{array}$ & $\begin{array}{c}\text { This report generates the no. of products } \\
\text { delivered for a particular date. }\end{array}$ \\
\hline $\begin{array}{c}\text { No. of Orders vs } \\
\text { Customer }\end{array}$ & $\begin{array}{c}\text { Compares the no. of orders with the unique } \\
\text { customer id. }\end{array}$ \\
\hline Sales \\
vs \\
Month
\end{tabular}

\section{ACKNOWLEDGEMENT}

Our thanks to the experts who have contributed towards development of this template.

\section{REFERENCES}

[1] Woodson, Paula, and Zizhong J. Wang. A Shopping Store Online Database System. Computing, Measurement, Control and Sensor Network (CMCSN), 2012 International Conference on. IEEE, 2012.

[2] Samal, Subhashree, and Swarna Prabha Jena. "Research on the Development of a New Shop Application Using Android." International Journal of Advanced Computer Research 4.1 (2014): 236.

[3] Shang, Weiyi, et al. "Mapreduce as a general framework to support research in mining software repositories (MSR)." Mining Software Repositories, 2009. MSR'09. 6th IEEE International Working Conference on. IEEE, 2009.

[4] Creating simple Report using BIRT

[5] Curry, Ambrose, et al. "Web services development method." U.S. Patent Application 10/171,173.

[6] Golfarelli, Matteo Open source BI platforms: a functional and architectural comparison. Springer Berlin Heidelberg, 2009.

[7] Zhang, Xuewang and Linlin Wang. "Key technologies for security enhancing of payment gateway." Electronic Commerce and Security, 2008 International Symposium on. IEEE, 2008. 